\title{
Origins of variation in conducted vasomotor responses
}

Hald, Bjørn Olav; Welsh, Donald G.; Holstein-Rathlou, Niels-Henrik; Jacobsen, Jens Christian Brings

Published in:

Pflügers Archiv - European Journal of Physiology

DOI:

10.1007/s00424-014-1649-1

Publication date:

2015

Document version

Early version, also known as pre-print

Citation for published version (APA):

Hald, B. O., Welsh, D. G., Holstein-Rathlou, N-H., \& Jacobsen, J. C. B. (2015). Origins of variation in conducted vasomotor responses. Pflügers Archiv - European Journal of Physiology, 467(10), 2055-2067.

https://doi.org/10.1007/s00424-014-1649-1 


\section{Origins of variation in conducted vasomotor responses}

\section{Bjørn Olav Hald, Donald G. Welsh, Niels-Henrik Holstein-Rathlou \& Jens Christian Brings Jacobsen}

Pflügers Archiv - European Journal of Physiology

European Journal of Physiology

ISSN 0031-6768

Pflugers Arch - Eur J Physiol DOI 10.1007/s00424-014-1649-1

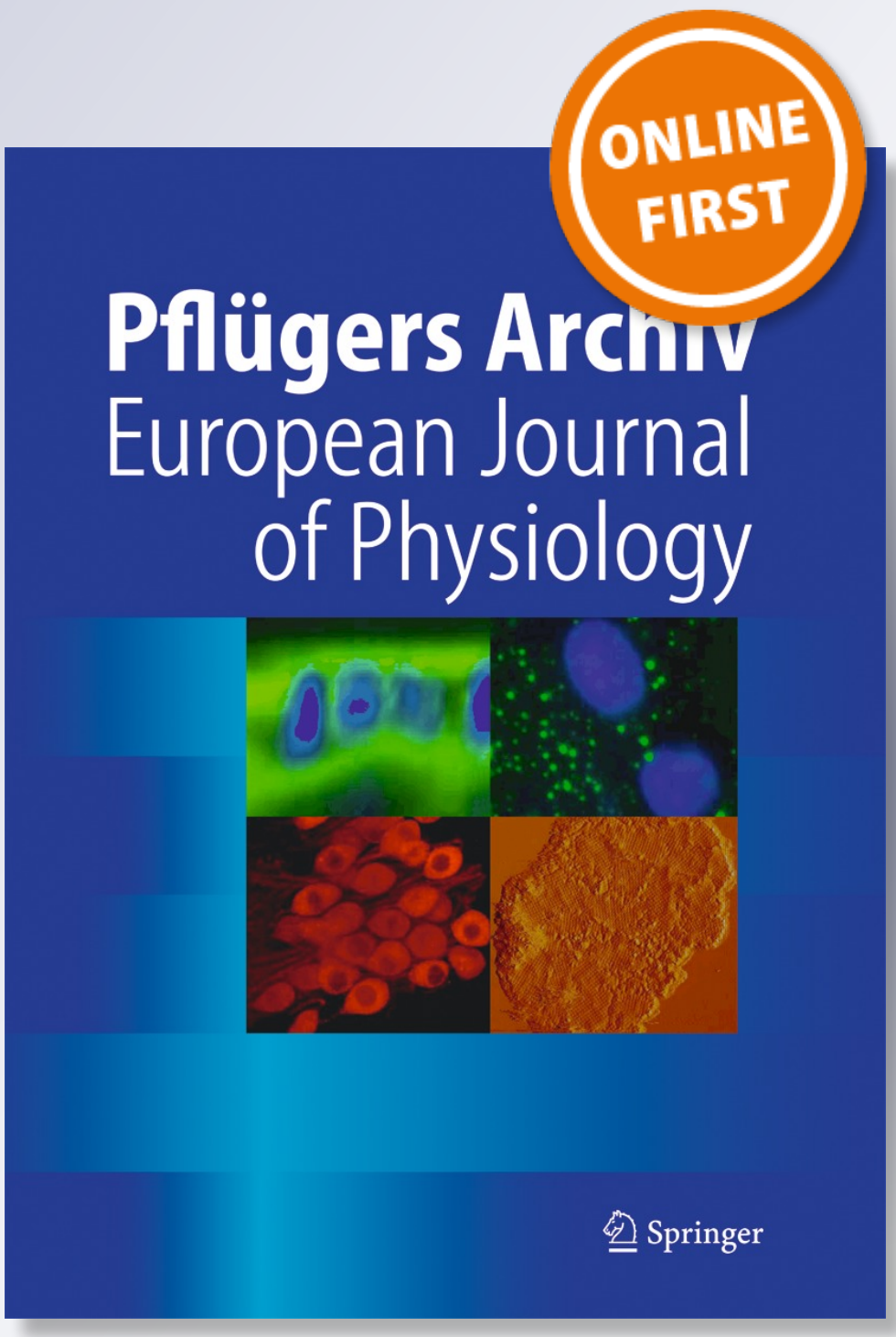

脰 Springer 
Your article is protected by copyright and all rights are held exclusively by SpringerVerlag Berlin Heidelberg. This e-offprint is for personal use only and shall not be selfarchived in electronic repositories. If you wish to self-archive your article, please use the accepted manuscript version for posting on your own website. You may further deposit the accepted manuscript version in any repository, provided it is only made publicly available 12 months after official publication or later and provided acknowledgement is given to the original source of publication and a link is inserted to the published article on Springer's website. The link must be accompanied by the following text: "The final publication is available at link.springer.com". 


\title{
Origins of variation in conducted vasomotor responses
}

\author{
Bjørn Olav Hald • Donald G. Welsh • \\ Niels-Henrik Holstein-Rathlou . \\ Jens Christian Brings Jacobsen
}

Received: 15 July 2014 / Revised: 9 October 2014 / Accepted: 7 November 2014

(C) Springer-Verlag Berlin Heidelberg 2014

\begin{abstract}
Regulation of blood flow in the microcirculation depends on synchronized vasomotor responses. The vascular conducted response is a synchronous dilatation or constriction, elicited by a local electrical event that spreads along the vessel wall. Despite the underlying electrical nature, however, the efficacy of conducted responses varies significantly between different initiating stimuli within the same vascular bed as well as between different vascular beds following the same stimulus. The differences have stimulated proposals of different mechanisms to account for the experimentally observed variation. Using a computational approach that allows for introduction of structural and electrophysiological heterogeneity, we systematically tested variations in both arteriolar electrophysiology and modes of stimuli. Within the same vessel, our simulations show that conduction efficacy is influenced by the type of cell being stimulated and, in case of depolarization, by the stimulation strength. Particularly, simultaneous stimulation of both endothelial and vascular smooth muscle cells augments conduction. Between vessels, the specific electrophysiology determines membrane resistance and conduction efficiency-notably depolarization or radial currents reduce electrical spread. Random cell-cell variation,
\end{abstract}

Electronic supplementary material The online version of this article (doi:10.1007/s00424-014-1649-1) contains supplementary material, which is available to authorized users.

B. O. Hald $(\bowtie) \cdot$ N.-H. Holstein-Rathlou · J. C. B. Jacobsen Department of Biomedical Sciences, University of Copenhagen, Blegdamsvej 3, 2200, Copenhagen, Denmark e-mail: bohald@sund.ku.dk

D. G. Welsh

Department of Physiology \& Pharmacology,

University of Calgary, Calgary, Canada ubiquitous in biological systems, only cause small or no reduction in conduction efficiency. Collectively, our simulations can explain why CVRs from hyperpolarizing stimuli tend to conduct longer than CVRs from depolarizing stimuli and why agonists like acetylcholine induce CVRs that tend to conduct longer than electrical injections. The findings demonstrate that although substantial heterogeneity is observed in conducted responses, it can be largely ascribed to the origin of electrical stimulus combined with the specific electrophysiological properties of the arteriole. We conclude by outlining a set of "principles of electrical conduction" in the microcirculation.

Keywords Conducted response - Gap junctions . Heterogeneity $\cdot$ Arteriole $\cdot$ Modeling

\section{Introduction}

Conducted vasomotor responses (CVRs) are believed to be important for flow regulation in the microcirculation. The mechanism is mediated by fast electrical signaling through intercellular gap junctions within the vascular wall and is independent of perivascular nerves or blood flow and pressure [2, 14, 16, 39]. The CVR is elicited by either mechanical or pharmacological stimuli that opens specific ion channels in the plasma membrane of vascular cells. Despite the universal electric component, the CVR displays a remarkable heterogeneity $[8,9,19,23]$. It is well-known that the endothelial cell (EC) layer is optimized for electrical spread in terms of cell-cell coupling and morphology as opposed to the overlying smooth muscle cell (SMC) layer $[11,17,21,26,39]$. The vasomotor response, however, requires that the electrical signal be transmitted from the EC layer to the SMC layer, through myoendothelial gap 
junctions (MEGJs) $[1,37]$ and/or by diffusion of vasoactive agents, e.g., NO or prostaglandins [12, 24]. The biophysical properties of the two cell types determine the overall electrical flows and partly explain why agonists acting on the EC layer produce stronger conduction compared to agonists acting on the SMC layer. Yet, different agonists acting on the same cell type within a single arteriole produce differences in CVRs [9]. Such differences are also observed using a single agonist applied to vessels from different vascular beds [8]. The roots of this heterogeneity are the focus of the present study. Whereas some variation is due to experimental procedures, e.g., differences in tissue trauma, exact temperature, perfusion solutions, etc., much heterogeneity is inherent to the biological systems in the form of cellular differences. Within the same cell type, general cell-cell variation in the composition of ion channels, exchangers, and pumps (collectively denoted ion transporters) exists. In a single vessel, the variation is mostly due to stochastic processes [29]. Between different vascular beds, pronounced variation in ion transporter furnishing may be found.

The control of parameters afforded by computational modeling facilitates studies of heterogeneity and function [18]. Here, we employ this approach using previously wellestablished models for the EC and SMC of the rat mesentery [21, 25, 34] to test the following hypotheses: (1) CVR variation is observed between vascular beds because ion channel furnishing is optimized to any given bed. Stochastic cell-cell variation within vessels of the same vascular bed does not give rise to CVR variation (in the former case the mean of one or more parameters is changed whereas only the standard deviation changes in the latter). (2) Agonists give rise to different CVRs because of their specific mode of action. For example, two agonists may show differences in their cellular target(s), their downstream current generating characteristics as well as activation/inhibition of additional ion transporters in the membrane. Introduction of structural, electrophysiological, and/or morphological heterogeneity enables a systematic investigation of the sources of the observed variation in the CVR. Our simulations show that the particular electrophysiology of a vascular bed determines the ability to conduct. For example, dissimilar endogenous resting membrane potentials $\left(\mathrm{V}_{\mathrm{m} \text {,rest }}\right)$ of the EC and SMC layers result in radial current flows that limit conduction. In terms of agonists, the targeted cell type(s) matter. Moreover, agonists that modulate ion transporters in the membrane may affect conduction if applied globally, but have only negligible effects if applied locally. Thus, heterogeneity in conduction as observed within a single vessel type derives mostly from how much and which cell type(s) is stimulated. Between different vessels, heterogeneity additionally derives from the variation in biophysical properties. Despite the diverse origins of variation, we conclude by extracting a set of "principles" for efficient conduction.

\section{Materials and methods}

A comprehensive model of a rat mesenteric arteriole with electrically sealed ends was developed based on previously published electrophysiological models [25, 34]. Morphology and diffusion were modeled as previously described $[19,21]$, i.e., one layer of ECs is surrounded by one layer of SMCs, see Fig. 1. SMCs are orientated perpendicular to the ECs and to the vessel length axis. The modeled vessel segment is $745 \mu \mathrm{m}$ long with a diameter of $124 \mu \mathrm{m}$ and consists of 96 ECs and 240 SMCs, each SMC and EC are divided into 8 and 20 segments, respectively. The total number of segments is therefore $96 \cdot 20+240 \cdot 8=2 \cdot 1920$. The mean myoendothelial gap junction (MEGJ) resistance is set to $900 \mathrm{M} \Omega$ per SMC, whereas homocellular gap junctional (GJ) resistances between ECs or SMCs are set to $3 \mathrm{M} \Omega$ and $90 \mathrm{M} \Omega$, respectively $[28,42]$ (homocellular GJ resistance is assumed to be homogeneously spread along the borders of the cell) [11]. These resistances are converted to permeabilities according to [25].

The first part of the vessel (denoted the vessel head), i.e., cells (ECs, SMCs, or both) located within the first $62 \mu \mathrm{m}$ of the vessel, was either voltage clamped to $-20 \mathrm{mV}$ or injected with current (typically $\pm 100 \mathrm{pA}$ per cell, see details below) to initiate a conducted response, i.e., a spread of current along the vessel from the stimulated site. Unless otherwise stated, the membrane potential $\left(\mathrm{V}_{\mathrm{m}}\right)$ profile of a conducted response was assessed in the SMC layer $1.0 \mathrm{~s}$ after the onset of stimulus. Conduction profiles were measured phenomenologically [21] using an exponential decay:

$V(x)=k\left(e^{\frac{-|y-x|}{\lambda}}+e^{\frac{-(y+x)}{\lambda}}+\frac{e^{\frac{-l}{\lambda}\left(\cosh \left(\frac{x+y}{\lambda}\right)+\cosh \left(\frac{y-x}{\lambda}\right)\right)}}{\sinh \left(\frac{l}{\lambda}\right)}\right)$

Equation 1 was used to fit only the conducted region, defined as the region beyond the initial $150 \mu \mathrm{m}$ of the vessel, in the SMC layer [21]. Equation 1 describes the electrical and not the mechanical vasomotor response.

In this study, we focus on electrical signalling in the arteriolar wall, i.e., we present the changes in $\mathrm{V}_{\mathrm{m}}$ that result from application of local electrical stimuli. We assume that the size of vasomotor response is reflected in the $\mathrm{V}_{\mathrm{m}}$ change. This is because the activity of voltage-gated $\mathrm{Ca}^{2+}$-channels (VGCCs) is a function of $\mathrm{V}_{\mathrm{m}}$. The resulting change in $\left[\mathrm{Ca}^{2+}\right]$ is followed by a vasomotor response, i.e., a vasodilatation upon hyperpolarization and vasoconstriction upon a depolarization [6]. The size of a vasomotor 

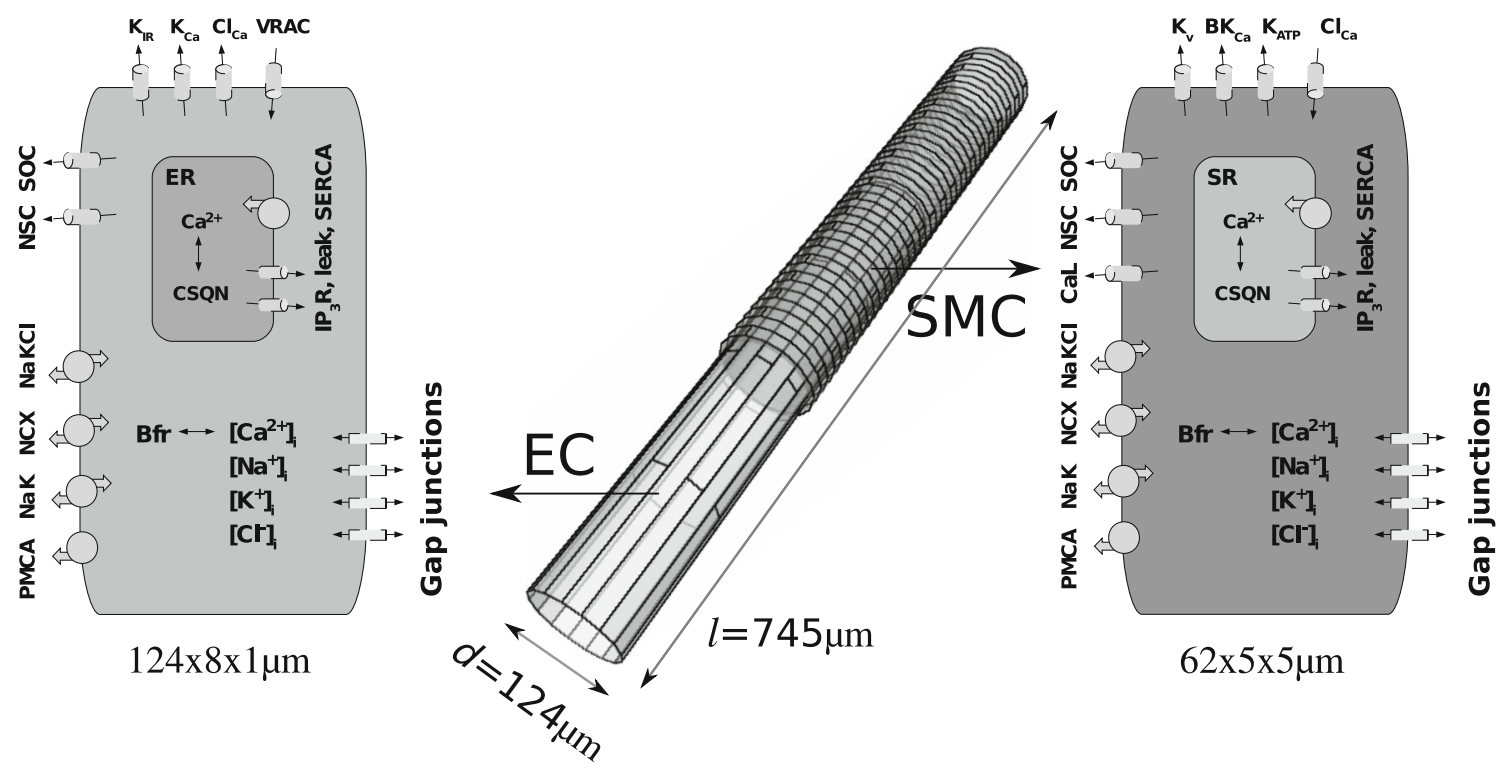

Fig. 1 Schematic drawing of the virtual vessel and its EC and SMC constituents. Ion transporter abbreviations are described in Table S1

response is therefore a monotone (but not necessarily linear) function of the degree of SMC polarization.

The system of ordinary differential equations was solved using SUNDIALS CVODE GM-RES solver (Lawrence Livermore National Laboratory, California) with relative and absolute tolerances of $10^{-4}$ and $10^{-9}$, respectively.

Heterogeneity The following types of cell-to-cell heterogeneity were considered:

In ion transporters: Variation in parameter values between individual cells was introduced using our previously described modeling strategy [18]. Specifically, for every ion transporter $j$, the parameter describing the maximal activity, $a_{\max , j}$, (see Table S1) was drawn from a normal distribution with a mean equal to the original model [19] and an standard deviation (SD) set to $k \cdot a_{\max , j}$, where $k \in[0.0,0.2]$.

In cell capacitance $\left(C_{\mathrm{m}}\right)$ or gap junctions (GJs):

Introduced as above in the $C_{\mathrm{m}}$ or maximal GJ/MEGJ activity of every EC and every SMC.

Furthermore, variations in the following parameters were considered:

Between EC-types: A previously published EC model is based on a mainly $\mathrm{Cl}^{-}$-type EC (predominantly $\mathrm{Cl}^{-}$driven) with a $\mathrm{V}_{\mathrm{m} \text {,rest }}$ around $-25 \mathrm{mV}$ [34]. As a range of endogenous resting potentials of ECs has been reported [31], we constructed a hyperpolarized $\mathrm{K}^{+}$-type EC $\left(\mathrm{V}_{\mathrm{m} \text {,rest }} \sim-65 \mathrm{mV}\right)$. Reducing the activity of the volume-regulated anion-channel (VRAC, see Table S1) by $90 \%$ and the inward-rectifying $\mathrm{K}^{+}$-channel $\left(\mathrm{K}_{\mathrm{IR}}\right)$ activity by $30 \%$ in the model, yielded a $\mathrm{V}_{\mathrm{m} \text {,rest }}$ of $-65 \mathrm{mV}$.

In the SMC layer: A permanent depolarization or hyperpolarization of the SMC layer was introduced by a constant injection of $+/-2.0 \mathrm{pA}$ into each SMC.0

In agonists: The following modes of current injections were used to simulate the different modes of action of different agonists: (1) Simple injection in either cell type or simultaneously in both cell types, (2) injection in both cell types as well as local/global inhibition of either VRAC and the non-specific cation-channel $\left(\mathrm{NSC}_{\mathrm{Na}}\right)$ upon hyperpolarization or the big conductance $\mathrm{Ca}^{2+}$-activated $\mathrm{K}^{+}$-channel $\left(\mathrm{BK}_{\mathrm{Ca}}\right)$ and voltage-gated $\mathrm{K}^{+}$-channel $\left(\mathrm{K}_{\mathrm{V}}\right)$ upon depolarization.

\section{Results}

Figure 2 shows $\mathrm{V}_{\mathrm{m}}$-profiles following either direct current stimulation or voltage clamp in either cell layer of the reference $\mathrm{Cl}$-type arteriole. The difference between a voltage clamp and a current injection is the amount of current given: In the former, the supply of current required to achieve a given voltage is essentially unlimited, while a fixed current is supplied in the latter. Hence, the $\mathrm{V}_{\mathrm{m}}$-response to a current injection will depend on the input resistance, e.g., a wellcoupled cell layer dampens the $\mathrm{V}_{\mathrm{m}}$-response and vice versa (see Fig. 2a, c). Stimulation of the SMC layer yields a large local response but poor signal conduction, while stimulation of the EC layer yields the most efficient conduction as previously reported [17, 21, 38, 39] but essentially no local response. Here, we define conduction efficiency as how 
Fig. 2 Biophysical properties of the cell layers and the type of stimulation determine the electrical spread. $\mathrm{V}_{\mathrm{m}}$-profiles in the SMC layer (full curves) and the EC layer (dotted lines) are shown for a Cl-type arteriole after $1.0 \mathrm{~s}$ of stimulation of either SMCs (a and b) or ECs (c and d) of the vessel head. In a and $\mathbf{c}$, either $+100 \mathrm{pA}$ (grey) or $-100 \mathrm{pA}$ (black) was injected. In $\mathbf{b}$ and $\mathbf{d}$, voltage clamp to either $-20 \mathrm{mV}$ (grey) or

$-90 \mathrm{mV}$ (black) was applied. The dashed grey lined represents the $V_{m, r e s t}$ of both EC and SMC layers. Note that current spread is efficient in the EC layer compared to the SMC layer

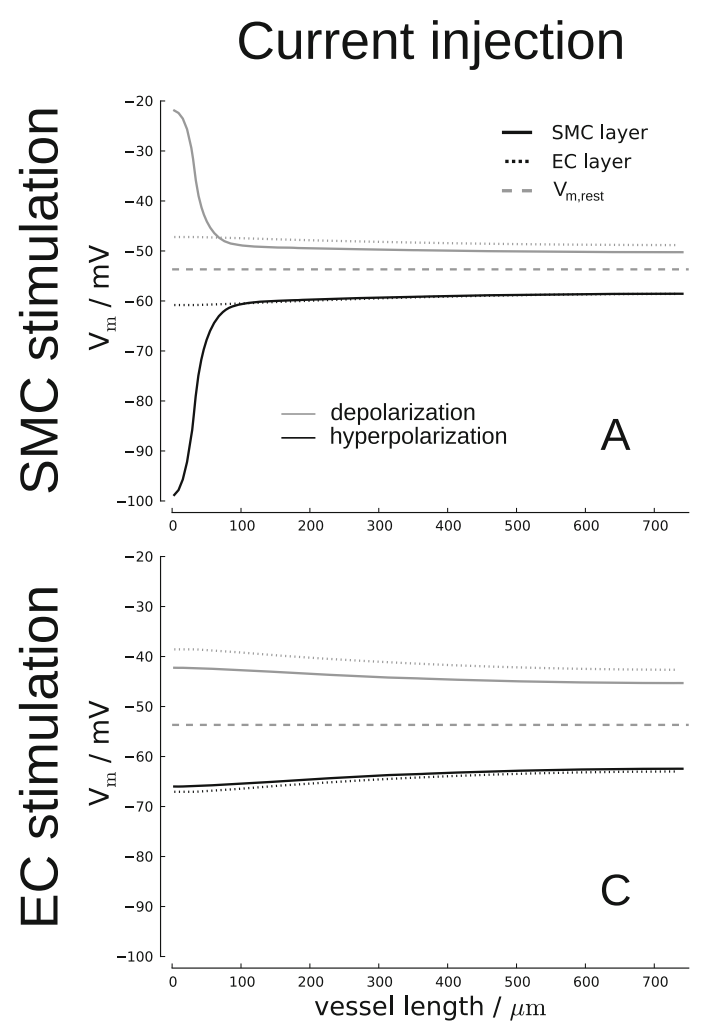

Voltage clamp
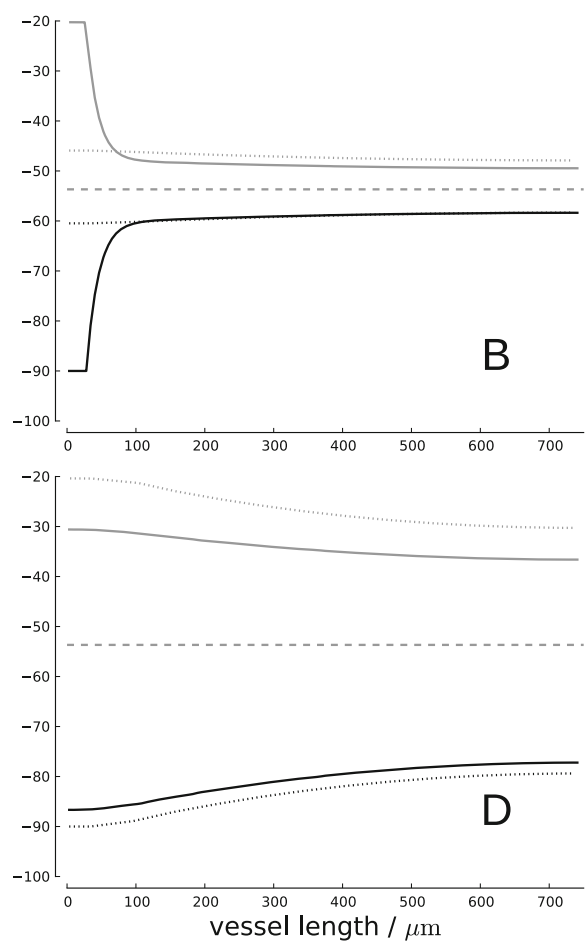

efficient a fixed amount of charge spreads along the vessel wall.

\section{Cell-cell variation: electrical heterogeneity}

Figure $3 \mathrm{a}$ shows conduction profiles in the SMC layer of a K-type arteriole with heterogeneity in ion transporter activities in response to a depolarizing current stimulation of both cell layers. Variation in ion transporter activities only slightly reduced electrical spread (grey curve) compared to a vessel without variation (black curve). The reduction in conduction happens because of the random occurrence of cells that dissipate more current compared to $\mathrm{SD}=0 \%$ cells (see insert). Upon hyperpolarizing stimuli, however, heterogeneity in ion transporters produced no significant reduction in conduction efficiency. Variation in other cellular parameters, e.g., homocellular gap junctional activity or cell capacitance, however, showed virtually no effect on conduction efficacy (Fig. S3). This is because the well-coupled EC layer effectively eradicate variation in local electrical properties.

Figure $3 b$ shows that conduction efficiency is proportional with the length of an EC because the EC layer is the main electrical pathway (conversely, the dimensions of the SMC are largely insignificant), i.e., the number of membranes to cross is proportional to the overall, average resistance of the cell layer. This value may differ between vascular beds.
Endothelial heterogeneity As some studies report individual ECs to be heterogeneous in terms of $\mathrm{V}_{\mathrm{m} \text {,rest }}[5,31]$, we constructed two "extreme" types of endothelium in terms

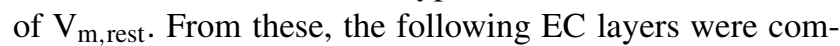
pared: (1) the $\mathrm{K}^{+}$-type $\mathrm{EC},(2)$ the $\mathrm{Cl}^{-}$-type $\mathrm{EC}$, and (3) a $50-50 \%$ mixture of the two types. Table 1 shows the reference membrane potentials of uncoupled ECs and SMCs as well as the coupled cells embedded in the arteriolar wall at steady state. The $\mathrm{V}_{\mathrm{m} \text {,rest }}$ of the Cl-type arteriole fits with $\mathrm{V}_{\mathrm{m} \text {,rest }}$ of pressurized arterioles from rat mesentery, measured to be around $-50 \mathrm{mV}[13,36]$. Table 1 also shows that large differences in membrane potential cannot be maintained within an electrically well-coupled tissue like the EC layer (with coupling, essentially no variation in $\mathrm{V}_{\mathrm{m} \text {,rest }}$ is observed). Indeed, even in a 50-50 \% K-/Cl-type EC layer with $20 \%$ ion transporter heterogeneity but without MEGJ coupling, the $\mathrm{SD}<0.15 \mathrm{mV}$ at steady state, illustrating the effectiveness of the well-coupled endothelium to smoothen out local electrical variation.

Reducing conduction efficiency: dissipating current flows A robust conducted vasomotor response balances two opposing requirements: First, conduction efficiency depends on charge spreading longitudinally within the EC layer. Second, the vasomotor response depends on sufficient charge being transferred to the SMC layer (force generation being dependent on input resistance, the open-probability profile and activity of VGCCs, and the $\mathrm{Ca}^{2+}$-sensitivity of the 


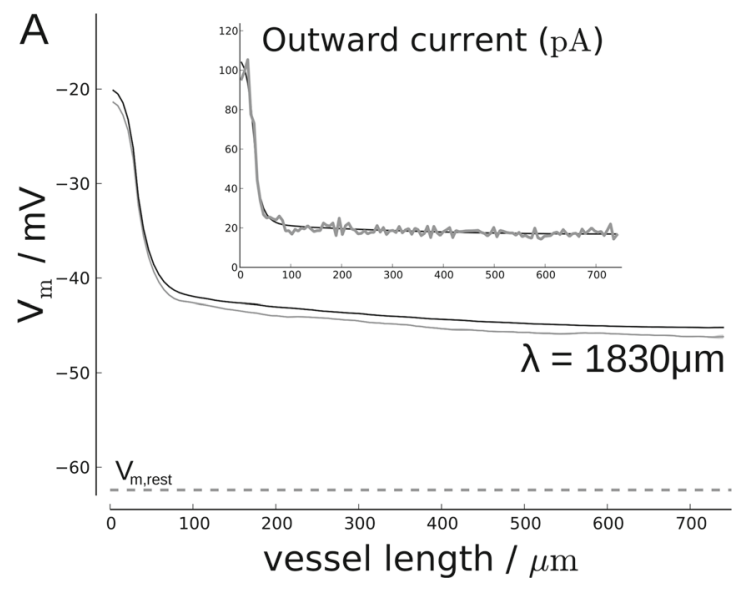

Fig. 3 Cell-to-cell variation has limited effect on conduction efficiency. a Variation in ion transporter activities slightly reduces electrical conduction due to local current leaks. SMC layer $\mathrm{V}_{\mathrm{m}}$ profiles of K-type arterioles with (grey) or without (black) $20 \%$ heterogeneity in ion transporter activities are displayed after $1.0 \mathrm{~s}$ of stimulation $(+100 \mathrm{pA}$ of cells of both cell layers of the vessel end). The grey curve represents the mean (dark grey) and standard deviation (light grey fill) of three independent arterioles (hardly visible). The dashed grey line represents $\mathrm{V}_{\mathrm{m} \text {,rest }}$. The insert shows that the reduced conduction efficiency results from random occurrences of leaky cells that dissipate more current across the

SMC). Thus, robust conduction is a balance between longitudinal spread (in the EC layer) and radial spread ("to" the SMC layer). If electrically uncoupled cell layers that display differences in $\mathrm{V}_{\mathrm{m} \text {,rest }}$ suddenly becomes electrically coupled, radial current flows ensue. Accordingly, MEGJs provide for global radial currents if the endogenous resting potentials between the EC layer and SMC layer are wide apart. With sufficient MEGJ permeability, the endogenous potentials of the cell layers collapse into a single $\mathrm{V}_{\mathrm{m} \text {,rest. }}$. To preserve energy, the membrane resistance $\left(R_{\mathrm{m}}\right)$ of vascular cells is likely to be largest at $\mathrm{V}_{\mathrm{m} \text {,rest }}$. Thus, membrane dissipation increases with differences between the endogenous $\mathrm{V}_{\mathrm{m} \text {,rest }}$ of a cell layer and the arteriolar $\mathrm{V}_{\mathrm{m} \text {,rest. }}$ In the Cl-type arteriole, radial currents are large as $\mathrm{V}_{\mathrm{m}, \text { rest }}^{\mathrm{EC}}-\mathrm{V}_{\mathrm{m}, \text { rest }}^{\mathrm{SMC}} \approx 34 \mathrm{mV}$, but they are small in the $\mathrm{K}$ -

Table 1 Computational steady state values of membrane potentials $\left(\mathrm{V}_{\mathrm{m}}\right.$ in $\left.\mathrm{mV}\right)$ in arterioles either without $(\mathrm{N})$ or with $(\mathrm{Y})$ homo- and heterocellular gap junctions. In both types of arterioles, ion transporter heterogeneity of either 0 or $20 \%$ was introduced. Standard deviations below $0.09 \mathrm{mV}$ were not included. $n=3$

\begin{tabular}{lcccccc}
\hline & \multicolumn{2}{c}{ SMC } & \multicolumn{2}{c}{ K-type EC } & \multicolumn{2}{c}{ Cl-type EC } \\
\cline { 2 - 7 } N 0\% & -59.4 & \multicolumn{2}{c}{-64.6} & -25.3 \\
N 20\% & $-59.6 \pm 3.2$ & \multicolumn{2}{c}{$-65.2 \pm 5.5$} & \multicolumn{2}{c}{$-28.8 \pm 10.5$} \\
\hline & SMC & K-type EC & SMC & Cl-type EC & SMC & Cl/K-type EC \\
\cline { 2 - 7 } Y 0\% & -62.4 & -62.8 & -53.7 & -52.9 & -55.8 & -56.1 \\
Y 20\% & -63.5 & -64.0 & -54.2 & -53.5 & -56.7 & -56.6 \\
\hline
\end{tabular}

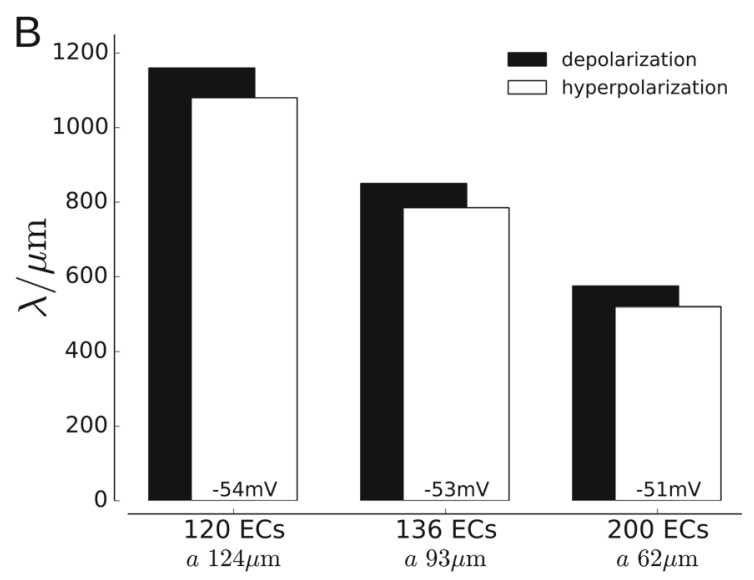

plasma membrane (see text). Figure S3 shows that similar heterogeneity in gap junctional conductances or cell capacitances virtually have no effect on conduction. Thus, high variation in a cellular parameter has limited effect on conduction. b Mean endothelial cell length impacts conduction efficiency. Reducing the length of an EC (here, a Cl-type) decreases conduction efficiency as more membranes to cross is equivalent to increased resistance. The length constant in the SMC layer following stimulation $\left(-100 \mathrm{pA}\right.$ in ECs of the vessel head). The arteriolar $\mathrm{V}_{\mathrm{m} \text {,rest }}$ is shown in the white bars.

type arteriole: $\mathrm{V}_{\mathrm{m} \text {,rest }}^{\mathrm{EC}}-\mathrm{V}_{\mathrm{m} \text {,rest }}^{\mathrm{SMC}} \approx-5 \mathrm{mV}$ (see Table 1). A similar difference in endogenous $\mathrm{V}_{\mathrm{m} \text {,rest }}$ may occur upon sustained but specific depolarization of a cell layer, e.g., the SMC layer upon discharge from sympathetic nerves. Hence, a depolarized SMC layer was constructed by permanently injecting $2 \mathrm{pA}$ into every SMC providing an endogenous $\mathrm{V}_{\mathrm{m}, \text { rest }}^{\mathrm{SMC}}$ of $-46 \mathrm{mV}$ (i.e., $\mathrm{V}_{\mathrm{m}, \text {,rest }}^{\mathrm{EC}}-\mathrm{V}_{\mathrm{m}, \text { rest }}^{\mathrm{SMC}^{*}} \approx 20 \mathrm{mV}$ ). Similarly, a hyperpolarized SMC layer was produced by a permanent injection of $-2 \mathrm{pA}$. These SMC layers were coupled to the K-type EC layer. Finally, a depolarized Cltype arteriole was also produced by inhibiting the activity of $\mathrm{K}^{+}$-leak and slightly reducing activities $\mathrm{K}^{+}$-channels of the SMCs (endogenous $\mathrm{V}_{\mathrm{m} \text {,rest }}^{\mathrm{SMC}^{*}}$ of $-50 \mathrm{mV}$ ). Figure 4 shows how overall electrophysiology, depolarization, and radial currents may alter $R_{\mathrm{m}}$ that ultimately affects conduction. The Cl-type arteriole displays weaker conduction efficiency compared to the K-type arteriole. Even upon depolarization of both arteriole types to the same $\mathrm{V}_{\mathrm{m} \text {,rest }}$, the K-type conducts better (compare Fig. 4b, e). Figure 4a to c shows that conduction efficiency is diminished by increasing depolarization (membrane conductance of depolarized cells increase due to increased activation of repolarizing currents, i.e., cells dissipate more current $[4,21])$. This tendency is summarized in Fig. 4f.

In general, dissipative flows are complex because they depend on the combined properties of all ion transporters and GJs. The $\mathrm{V}_{\mathrm{m} \text {,rest }}$ depends on steady state flows 

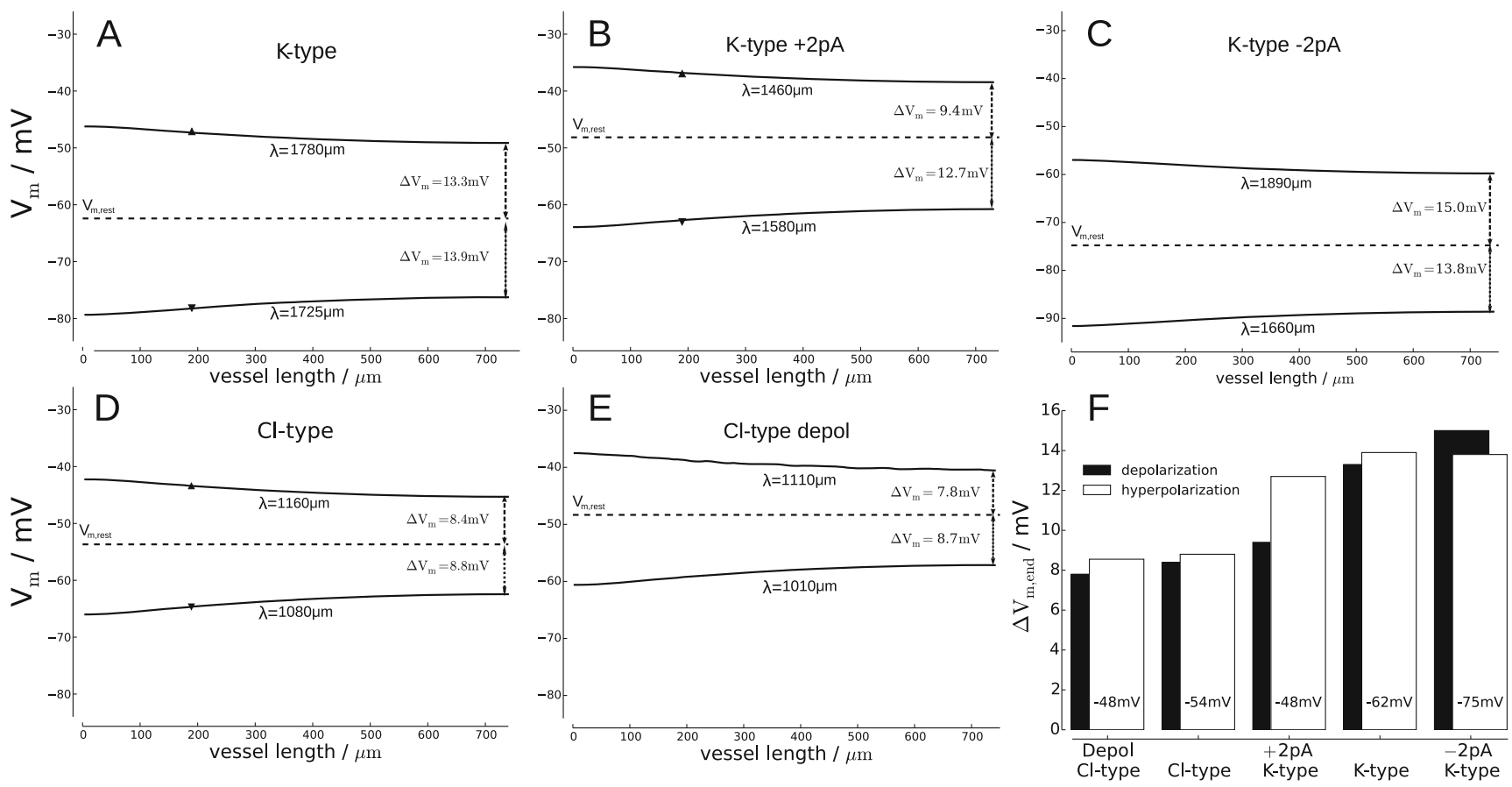

Fig. 4 Depolarization of $\mathrm{V}_{\mathrm{m} \text {,rest }}$ and radial currents decrease conduction efficiency. $100 \mathrm{pA}$ of either depolarizing (upper curves) or hyperpolarizing (lower curves) current was injected for $1.0 \mathrm{~s}$ into ECs in vessel heads with different electrophysiological properties $\left(\mathrm{V}_{\mathrm{m}}\right.$,rest $\mathrm{s}$ are shown as dashed lines). The resulting conduction profiles in the SMC layers of the arteriole and the corresponding length constants using Eq. 1 are shown. Also, the relative efficiency of conduction is reflected in the distal polarization change, $\Delta V_{\mathrm{m} \text {,end }}=\mid \mathrm{V}_{\mathrm{m}, \text { end }}-$ $\mathrm{V}_{\mathrm{m} \text {,rest }} \mid$, where $\mathrm{V}_{\mathrm{m} \text {,end }}$ is the membrane potential of the distal SMC and $V_{m, r e s t}$ is the resting potential, is shown for each $V_{m}$-profile. a K-type arteriole. b Depolarized K-type arteriole: the SMC layer in a

of ionic species across the membrane. A perturbation of $\mathrm{V}_{\mathrm{m}, \text { rest }}$ is counteracted by resetting currents, e.g., repolarizing currents upon depolarization. Strong counteracting feedback currents decrease conduction efficiency. Figure 4 illustrates that both the specific furnishing of ion transporters, $\mathrm{V}_{\mathrm{m} \text {,rest }}$ as well as sustained endogenous differences between the EC and SMC layers influence conduction efficiency.

Agonist variation: heterogeneity in stimuli

To test the hypothesis that the variation in conduction efficiency observed in the same vessel exposed to different agonists, e.g., acetylcholine, bradykinin, adenosine, etc., reflects their particular modes of action, three simple sets of simulations were set up.

Mode of action: effect of cell type(s) being stimulated Figure $5 \mathrm{a}$ and $\mathrm{b}$ display reference $\mathrm{V}_{\mathrm{m}}$-profiles following current injection of $\pm 100 \mathrm{pA}$, respectively, into the EC layer as a dashed black line. Stimulation of both layers (fully drawn lines) boost signal conduction. A combination
K-type arteriole was depolarized permanently by injecting $+2 \mathrm{pA}$ into each SMC. c Hyperpolarized K-type arteriole: Permanent injection of $-2 \mathrm{pA}$ into each SMC. d Cl-type arteriole. e Depolarized Cl-type arteriole: Reducing particularly $\mathrm{K}^{+}$-channel activities, a depolarized arteriole was constructed with the same $\mathrm{V}_{\mathrm{m} \text {,rest }}$ as in (b). f Summary plot showing conduction efficiency in terms of $\Delta V_{m \text {,end }}$. The $V_{m \text {,rest }}$ of the SMC layer of the arteriole is indicated in each bar. Compared to the K-type arteriole, conduction efficiency decreases by depolarization and even more in the Cl-type arteriole. This shows that both radial current flow and depolarization tend to increase charge dissipation and hence, impair conduction

of two factors increase the local charge availability within the EC layer leading to a conduction boost as observed by the increase in $\Delta \mathrm{V}_{\mathrm{m} \text {,end }}$ : First, no current from the EC layer is now required to produce the local $\mathrm{V}_{\mathrm{m}}$-response in the SMC layer. Second, as seen in Fig. 2, stimulation of the well-coupled EC layer produces a weak local $\mathrm{V}_{\mathrm{m}}$ response but efficient conduction whereas SMC stimulation gives rise to a strong local $\mathrm{V}_{\mathrm{m}}$-response but weak conduction. Given similar magnitudes of stimulation within the two layers, a local electrical gradient is therefore generated, providing an additional charge flow from the SMC layer to EC layer through MEGJs at the local site (see insert), thereby enhancing conduction. The fully drawn grayscale curves in Fig. 5 illustrate that the conduction boost depends on the size of the simultaneous stimulation of the SMC layer.

Upon a depolarizing stimulus, the boost also (albeit to a lesser extent) depends on level of SMC-SMC coupling or, similarly, on the area of SMC layer that is stimulated (e.g., $50 \mathrm{pA}$ injected across twice as many SMCs). Both leads to a smaller $\mathrm{V}_{\mathrm{m}}$-response, i.e., less dissipation due to opening of repolarizing channels. 


\section{Depolarization}

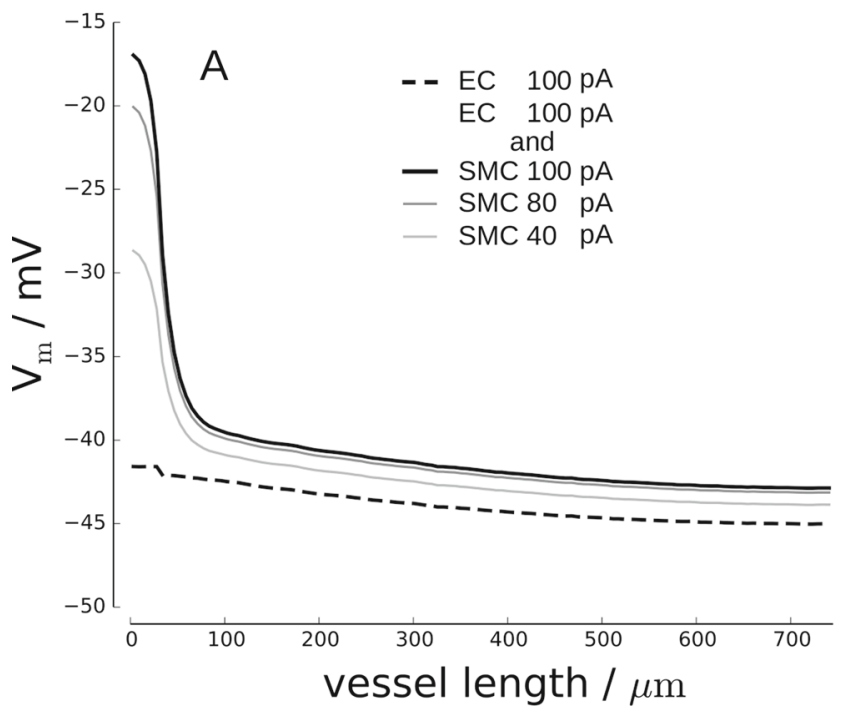

Fig. 5 The cell type targeted by an agonist affect conduction. A current injection into either (1) ECs (black dashed curve) or (2) simultaneously into ECs and SMCs (full curves, see legend for injected currents) of the vessel head results in stronger conduction profiles. This reflects the comparably low and high coupling resistances in the EC and SMC layers, respectively (see text for details).

Mode of action: amount of current generated Similarly, charge availability also depends on the concentration of a specific agonist as well as its ability to generate current upon stimulation of a cell. Due to voltage-gated ion channels, the relation between current input and current dissipation need not be linear. Figure 6 displays $\Delta \mathrm{V}_{\mathrm{m} \text {,end }}=\left|\mathrm{V}_{\mathrm{m} \text {,end }}-\mathrm{V}_{\mathrm{m} \text {,rest }}\right|$ as a proxy for conduction efficiency in three types of arterioles, namely the Cl-type and $\mathrm{K}$-type arterioles as well as the depolarized K-type arteriole. Again, the effect of different electrophysiologies on conduction is clearly visible. Conduction efficiency decline with increasing depolarizing current injections (decreasing curvature in Fig. 6a), i.e., the relative charge dissipation increases with the strength of the stimulus as expected. The lack of resetting ion channels that would open in response to hyperpolarization explains why increasing hyperpolarizing stimuli do not change conduction efficiency to any significant extent (Fig. 6b).

Consequently, electrical spread depends on (1) the local coupling characteristics (Fig. S4), (2) the mode of action of an agonists, i.e., which cells are targeted (Fig. 5), and (3) the specific electrophysiology including how much current is generated (Fig. 6).

Agonist modulation of ion channels In the final set of simulations, the local current injection was combined with either

\section{Hyperpolarization}

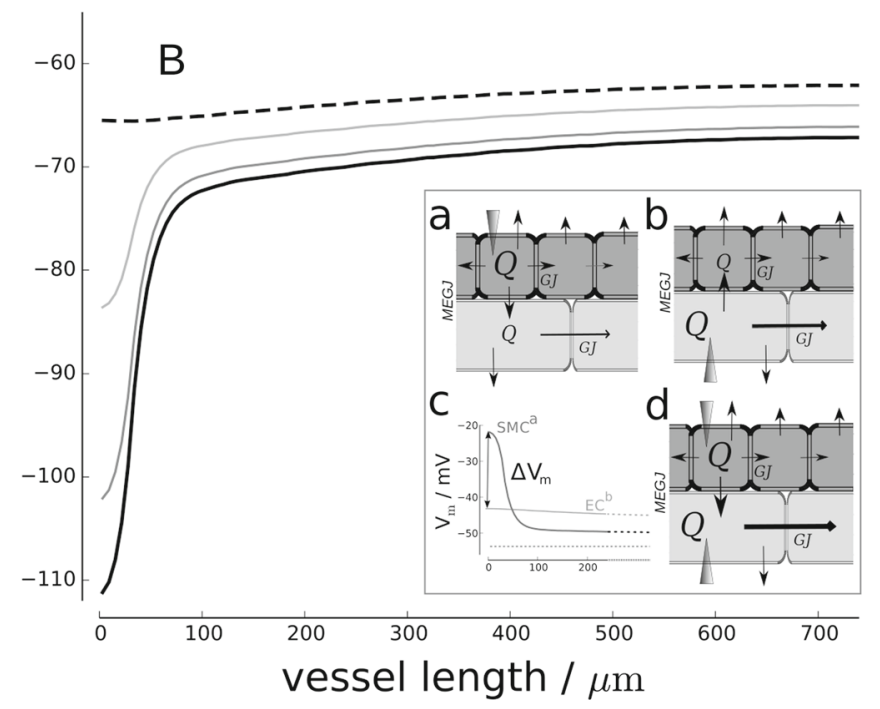

a Depolarizing current of $100 \mathrm{pA}$ used. b Hyperpolarizing current of $100 \mathrm{pA}$ used. The insert shows that stimulation of the SMC layer (a) produce a strong local response whereas EC layer stimulation (b) produces a weak local response but strong conduction. Thus, dual stimulation produces an extra current gradient towards the EC layer (c), i.e., making more charge available for longitudinal spread (d)

$100 \%$ inhibition or $100 \%$ activation of two specific ion channels (two ion channels giving strong currents opposing the perturbation were selected to emphasize the effect). Upon hyperpolarization, we chose the $\mathrm{NSC}_{\mathrm{Na}}$ and VRAC, in the model, these channels are constitutively active but they also display strong inward currents upon hyperpolarization. Upon depolarization, we chose the repolarizing $\mathrm{BK}_{\mathrm{Ca}}$ and $\mathrm{K}_{\mathrm{V}}$ channels. Figure 7 shows that upon local stimulation of both cell layers, the additional local inhibition/activation of these channels gave rise to significant changes in the local response but almost no change at the distal site. The surplus of charge obtained by the local inhibition of few channels induces a stronger local $\mathrm{V}_{\mathrm{m}}$-response that in turn opens other ion channels and consequently limits the gain in longitudinal spread of charge (compared to the whole vessel, the small decrease in local charge dissipation is negligible). On the other hand, a global activation or inactivation of these ion channels across the whole vessel had a large impact on electrical spread (dashed black lines) as previously described $[2,19,39]$.

\section{Discussion}

The well-coupled endothelium and the morphological layout of ECs and SMCs are known to be crucial for efficient electrical spread along the vascular wall $[11,17$, 


\section{Depolarization}

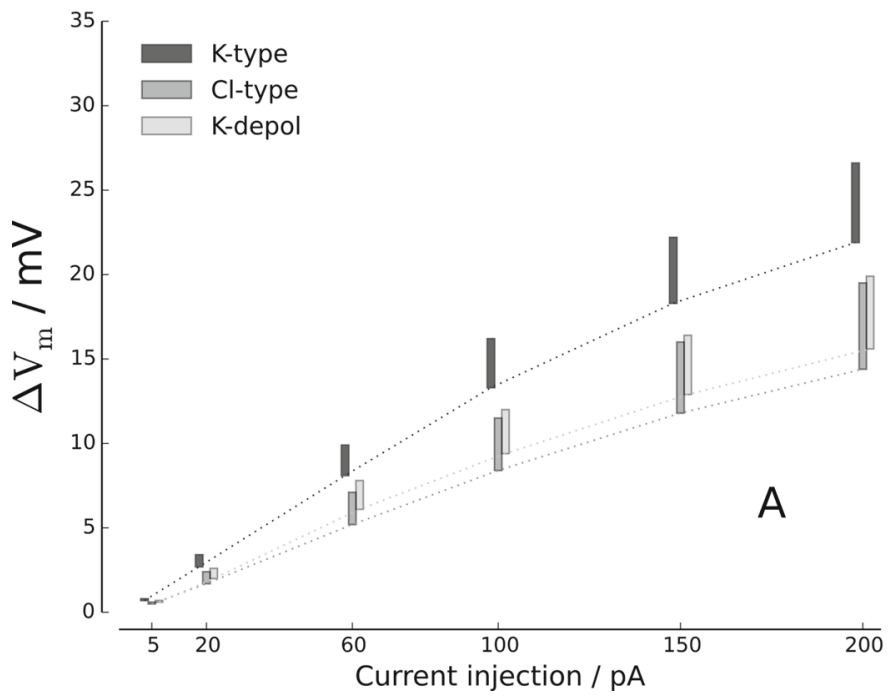

Fig. 6 Stimulus strength may affect conduction efficiency. The local and vessel-end responses (relative to $\mathrm{V}_{\mathrm{m}, \text { rest }}$ ) in (1) a $\mathrm{K}$ type arteriole (dark grey), (2) a Cl-type arteriole (grey) or (3) a depolarized K-type arteriole (light grey) are shown as a function of increasing levels of a local current stimulus into the EC layer of the vessel head. A box displays $\Delta \mathrm{V}_{\mathrm{m}}=\left|\mathrm{V}_{\mathrm{m} \text {,local }}-\mathrm{V}_{\mathrm{m} \text {,end }}\right|$

41]. Yet, despite decades of research, the question of why conduction is heterogeneous within and among vascular beds remain largely unresolved [8, 9, 14]. Recently, we showed that conduction depends on stimulus strength, resting membrane potential as well as global ion channel modulation [19]. Building on those findings, the present study shows that observed heterogeneity within a single type of vessel derives from different modes of agonist action, particularly in terms of cellular target(s) and current generation. Heterogeneity between different vessel types may additionally derive from different electrophysiological, morphological, and/or biophysical properties. Finally, variation in conduction is unlikely to be based on ubiquitous cell-cell variation or any additional ion transporter modulations induced locally by an agonist.

Biophysics govern the fundamental charge flows Figure 2 emphasizes the critical dependence on the EC layer for electrical spread and cellular morphology as previously reported $[17,38,39]$. MEGJ coupling provides for the subsequent polarization of the SMC layer (Fig. S1) [20]. Extensive intercellular coupling decreases input resistance. In turn, this reduces the local change in $\mathrm{V}_{\mathrm{m}}$ in response to a current perturbation (Figs. 2c and 5). In isolated EC tubes, current in the nano-ampere range can be easily injected into a single EC [2], demonstrating that gap junctions are generally open pores with high current conductance in the EC layer.

\section{Hyperpolarization}

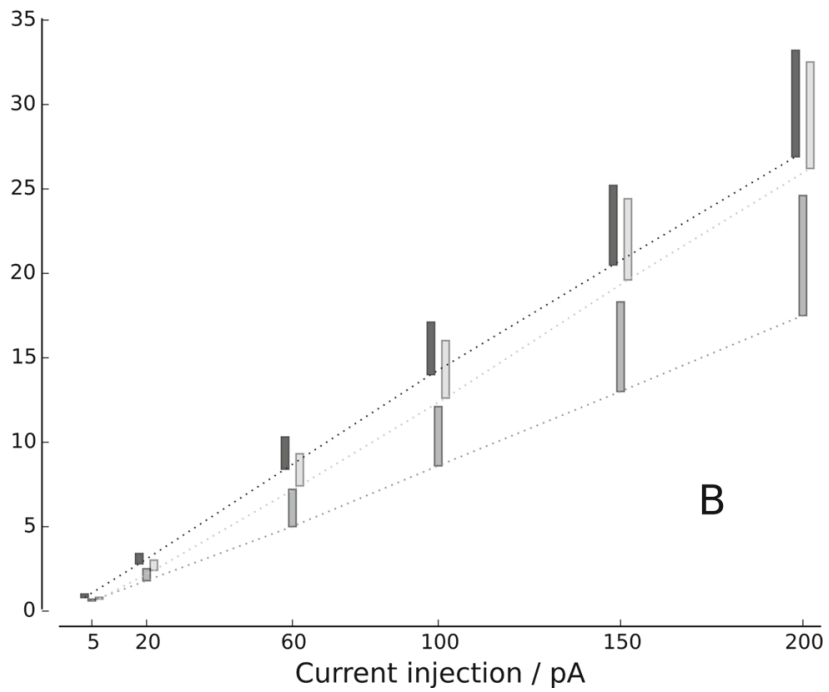

relative to $\mathrm{V}_{\mathrm{m} \text {,rest }}=0 \mathrm{mV}$, i.e. the upper and lower parts show the local and vessel-end amplitudes, respectively. a High depolarization strength decreases conduction. The curvature implies that current dissipation increases with higher input currents resulting in less efficient conduction. b Hyperpolarization strength only slightly affects conduction efficiency

\section{Agonist heterogeneity}

Figures 2, 5, and 6 suggest that a major source of variation in electrical spread within the same type of vessel derives from the mode of action of an agonist, particularly cellular targets and current generation.

Cell target of stimulation Stimulation of a given cell type, i.e., ECs, SMCs or both simultaneously, give rise to large differences in conduction reflecting the coupling within the given cell layers (Figs. 2 and 5). Accordingly, a set of observational rules may be put forth for stimuli that produce a change in $\mathrm{V}_{\mathrm{m}}$ : (1) Observation of a local (electrical) response with weak conduction is likely caused by an agonist that activates the SMC layer only. (2) Observation of strong conduction without a local response is caused by an agonist that activates the EC layer only. (3) Observation of a local response with strong conduction is likely caused by an agonist that directly or indirectly activates both cell layers. Observation of a local response without conduction can also be induced by non-electrical agonists, e.g., by modulation of $\mathrm{Ca}^{2+}$-sensitivity [6]. Notably, simultaneous stimulation of both cell types causes a conduction boost (Fig. 5) as the strong local response in the SMC layer produces an electrical gradient to the underlying EC layer. This boost may be important in relation to conduction induced by various paracrine and metabolic effectors. 


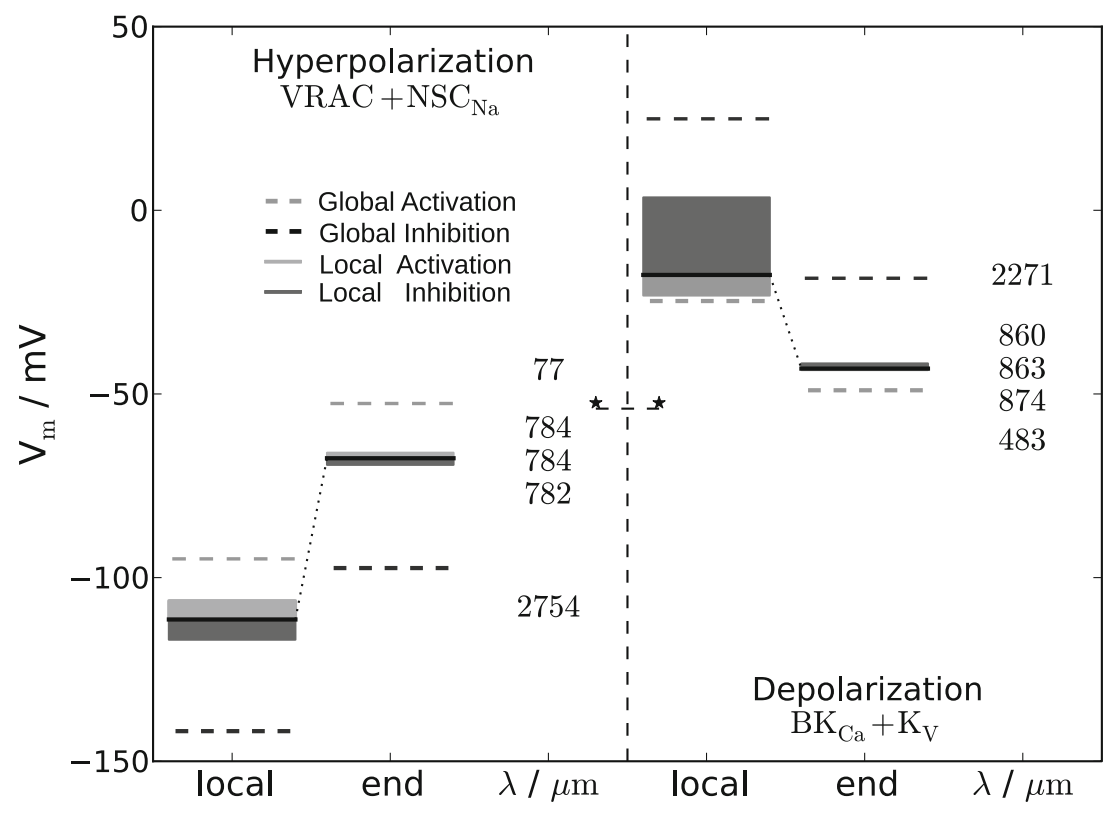

Fig. 7 Local and global ion channel modulations. 100 pA of hyperpolarizing or depolarizing current was injected to both ECs and SMCs of the vessel head with or without $\left\{\mathrm{VRAC}\right.$ and $\left.\mathrm{NSC}_{\mathrm{Na}}\right\}$ or $\left\{\mathrm{BK}_{\mathrm{Ca}}\right.$ and $\left.\mathrm{K}_{\mathrm{V}}\right\}$ activity modulation. The local and distal membrane potential as well as the length constant, $\lambda$, are shown in the columns. Activity of either $\left\{\right.$ VRAC and $\left.\mathrm{NSC}_{\mathrm{Na}}\right\}$ (hyperpolarization, left) or $\left\{\mathrm{BK}_{\mathrm{Ca}}\right.$ and $\left.\mathrm{K}_{\mathrm{V}}\right\}$ (depolarization, right) was either normal (control, full black lines), $100 \%$ activated locally (light grey) or $100 \%$ inhibited locally (dark grey). The size of the grey boxes denote the difference from control. Global activation or inhibition across the entire vessel is also shown as dashed grey and dashed black lines, respectively. The stars ( $\star$ ) denote the resting potential of the Cl-type arterioles
Particularly, it can explain the strong conduction of ACh. Although muscarinic activation depolarize isolated SMCs, strong ACh-induced hyperpolarization of SMCs is evident in intact vessels. This is due to direct electrical coupling through MEGJs and to the release of substances from the EC layer that subsequently hyperpolarize the SMC layer, e.g., prostaglandins, eicosanoids, and NO [12, 24]. Although EC dependent, the latter means of SMC hyperpolarization increase charge availability locally in the EC layer, leading to a conduction boost. The direct and indirect stimulation of the EC and SMC layers, respectively, explains (at least partly) the strong conduction induced by $\mathrm{ACh}$. Indeed, this mechanism fit with experimental observations showing that inhibition of diffusible factors from the EC layer increases ACh-induced conduction decay [24, 40]. Moreover, it can also explain why direct current injection in the EC layer produce weaker conduction $(\lambda \sim$ $1.2 \mu \mathrm{m})$ compared to a similar level of local hyperpolarization induced by ACh $(\lambda \sim 1.9 \mu \mathrm{m})$ in hamster feed arterioles [14].

Amount of generated current We have previously shown that the size of a depolarizing stimulus is inversely related to conduction efficiency [19]. In case of hyperpolarization, however, the stimulus strength did not affect conduction efficiency (Fig. 6b). Depolarization induces activation of repolarizing currents [4] but no analogous currents are found upon hyperpolarization. Therefore, increasing depolarization but not hyperpolarization induce a decrease in conduction efficiency (the nonlinearity in the current dissipation/retain ratio upon depolarization also explains why ion transporter heterogeneity reduces conduction in Fig. 3a). The difference ultimately depends on the particular furnishing of ion transporters. For example, hyperpolarizationactivated cyclic nucleotide-gated ion channels introduce nonlinearity in the current dissipation/retain ratio in the hyperpolarized region and such channels have been found in, e.g., lymphatic SMCs [30]. Therefore, other vascular beds may behave differently from rat mesenteric arterioles upon hyperpolarization. In the depolarized region, however, we expect the finding to be robust due to the universal occurrence of repolarizing channels. A strong depolarizing stimulus is therefore associated with a lower conduction efficiency because $R_{\mathrm{m}}$ is reduced both locally and beyond. As charge spreads from the stimulation site, however, the decline in charge density reduces the $\mathrm{V}_{\mathrm{m}}$ response, i.e., $R_{\mathrm{m}}$ increases. Therefore, conduction efficiency improves with greater distance from the stimulation site [21], i.e., a strong stimulus conducts longer than a weak stimulus [21].

The total amount of current generated by an agonist depends on (1) the number of stimulated cells [39], (2) the local concentration of agonist, and (3) the ability of the agonist to generate current. Variation in current generation may 
in turn explain some of the variability between experiments. Particularly, both pressure ejection and microiontophoresis can produce relatively large differences in drug delivery depending on the micropipette tip, the ejection time, and the flow rate of the perfusate [22]. Indeed, microiontophoresis of ACh has been observed to extend up to $100 \mu \mathrm{m}$ in both directions from the pipette tip [27] which likely adds to the strong conduction induced by ACh. Finally, current may also be induced by external changes in electrolyte concentrations that change Nernst potentials. Specifically, a voltage clamp works either by injection of a suitable amount of current that clamps the potential or by "clamping" the Nernst potentials (partly obtained by $\mathrm{KCl}$ addition). Current generation and voltage clamping are thus fundamentally different: Despite the current injection of $100 \mathrm{pA}$ and voltage clamp to $-20 \mathrm{mV}$ give rise to similar local responses in the SMC layer (Fig.2a, b), the local responses in the highly conducting EC layer are dissimilar (Fig. 2c, d-a difference from -38 to $-20 \mathrm{mv}$ ).

Modulation of ion transporter activity An agonist may modulate, i.e., activate, or inhibit more than one ion transporter. Thus, we hypothesized that an agonist could enhance electrical conduction by limiting current dissipation locally in addition to current generation and vice versa. However, combining current injection with a local modulation of two ion channels that display strongly opposing currents does not significantly change conduction efficiency (Fig. 7). This is a consequence of the plethora of cellular ion channels: If a few ion channels that restore $V_{m \text {,rest }}$ are inhibited locally, the local response is enhanced which in turn increases the open probability of other $\mathrm{V}_{\mathrm{m} \text {,rest }}$-restoring ion channels. Thus, a large portfolio of ion channels need be affected locally to limit total dissipation and thereby increase conduction efficiency. On the other hand, a global alteration of one or more ion channels may significantly change conduction efficiency (Fig. 7) as previously described [2, 19]. Modulation of ion transporters may appear in two principally different flavors: (1) Modulation of constitutively active ion transporter(s) that maintain the resting potential, e.g., the $\mathrm{Na} / \mathrm{K}$ exchanger or non-specification channels. Global application of such an agonist changes the endogenous $V_{m}$,rest of the cell layer and may have pronounced effect on communication along the vessel (Fig. 4) [2, 19]. For instance, although different isoforms of (e.g., T- and L-types) VGCCs exist, the open probability for all isoforms increases approximately in the same $\mathrm{V}_{\mathrm{m}}$-range, i.e., a global depolarization to $\sim-30 \mathrm{mV}$ not only produce constriction but also increase the sensitivity to additional depolarizing stimuli. (2) Modulation of ion channels that restores $V_{m}$ subsequent to a perturbation, e.g., repolarizing $\mathrm{K}_{\mathrm{V}}$-channels. Such channels have a modest influence on $\mathrm{V}_{\mathrm{m} \text {,rest }}$ itself but affect how strongly a cell "opposes" a change in $V_{m}$,rest (or equivalently restores $\mathrm{V}_{\mathrm{m} \text {,rest }}$ ). Hence, inhibition of such channels limits current dissipation and increases longitudinal spread along the vessel. It may be speculated that some agonists operate predominantly by a global modulation of conduction ability (i.e., the second "flavor") instead of directly by generating current.

\section{Systemic heterogeneity}

Variation in electrical spread also derives from differences in electrophysiological or morphological properties between vascular beds. The different furnishing or activity of ion channels may substantially affect the dynamic range of conduction (Figs. 4 and 6). Obviously, conduction efficiency is sensitive to EC-EC coupling (Fig. S5), but EC length is equally important (Fig. 3b), and recently we studied the importance of MEGJs in shaping the $\mathrm{V}_{\mathrm{m}}$-profile in the SMC layer [20]. Finally, subtle changes in the particular SMC-SMC or MEGJ coupling may influence conduction depending on stimulus (Fig. S4).

Heterogeneity in endogenous $V_{\mathrm{m} \text {,rest }}$ Provided that MEGJs are present, electrical spread is determined by the interplay between the overall ion transporter furnishing within the EC and the SMC as well as the intercellular coupling properties. Figures 4 and Fig. 6 illustrates that conduction is affected by depolarization and the radial currents that arise due to different endogenous $\mathrm{V}_{\mathrm{m} \text {,rest }}$ (although the K-type endothelium may be somewhat hypothetical, arterioles of very hyperpolarized ECs have been observed [7, 13]. Yet, the $\mathrm{V}_{\mathrm{m} \text {,rest }}$ evidently differs between vascular beds $[9,16$, $36,41]$ and differences between the endogenous $V_{m}$,rest of each layer are likely to occur). For instance, tonic discharge of noradrenaline from sympathetic nerves may depolarize the SMC layer. The consequent reduction in conduction efficiency (Fig. 4) is a function of two complementary effects: (1) The endogenous difference in $V_{m}$,rest between the EC and SMC layers provide for radial current flows that dissipate charge, thereby diminishing electrical spread (Fig. 4b). The added cost in conduction efficiency suggests that the endogenous resting potentials of the EC and SMC layers should be relatively similar. (2) In some regions of $V_{m \text {,rest }}$, the regulation of $V_{m}$ may be stronger than in others, i.e., a perturbation of $V_{m \text {,rest }}$ from, e.g., -50 to $-40 \mathrm{mV}$ show weak decay to steady state compared to a perturbation from, e.g., $\mathrm{V}_{\mathrm{m} \text {,rest }}=-40 \mathrm{mV}$ to $-30 \mathrm{mV}$ because of differential activation windows of highly conducting ion channels (in this case repolarizing $\mathrm{K}^{+}$-channels) [4, 19]. Current dissipation and hence, conduction efficiency, is a complex function of the particular ion transporter furnishing and $\mathrm{V}_{\mathrm{m}}$.

In terms of endothelium, the "type" of EC layer also affects conduction properties (Fig. 4b). It has been 
reported that individual ECs within some EC layers have unequal $\mathrm{V}_{\mathrm{m} \text {,rest }}$. At steady state, however, heterogeneity in $\mathrm{V}_{\mathrm{m}}$ within the EC layer is not consistent with an integrated and well-coupled EC layer (see, e.g., Table 1).

Electrical heterogeneity Heterogeneity in the maximal activity of plasma membrane ion transporters slightly reduces conduction in the depolarized region (Fig. 3) because of the random occurrence of "leaky" cells. Other cells will be more resistant to charge loss but as the leak/retain-relationship is nonlinear (the slope of the IVcurve is larger than unity) charge dissipation is larger than charge conservation. Only leaky SMCs are observed as the high input resistance produce slight differences in the $\mathrm{V}_{\mathrm{m}}$ profile. Regarding other kinds of electrical heterogeneity, e.g., in gap junction conductance or cell capacitance, virtually no effects on longitudinal spread of charge were observed (Fig. S3).

Additional SMC layers The effect of additional SMC layers (all else being equal) has previously been shown to increase the electrical decay [26, 41]. This is due to dilution of charge: increasing the number of cells that receives charge diminishes the $\mathrm{V}_{\mathrm{m}}$-response in those cells. The relative importance of SMC-SMC coupling also increase with more SMC layers. Recently, we showed that vessels with relatively few MEGJs must compensate by increasing the SMC-SMC coupling to maintain a smooth electrical response along the vascular wall [20]. With more SMC layers, however, SMC-SMC coupling needs not be large because current need only spread to a limited number of cells in the radial direction.

Function of MEGJs in conduction The existence of MEGJ and their ability to facilitate charge flows between cell layers are well documented [32]. Most studies point to a decisive functional role for MEGJs in facilitating direct feedback between the two layers $[1,13,37]$. In vitro, classical CVR studies show evidence of instantaneous radial electrical communication [14, 15]. In vivo, however, the extent of coupling between endothelial and smooth muscle cells has been disputed [3, 10, 33]. Based on the observation that $\mathrm{V}_{\mathrm{m}}$ is different in the two cell layers, it has been suggested that the electrical coupling between the layers is weak. We have previously shown that strong MEGJ coupling may be suboptimal as it diminishes both conduction efficiency [18] and the ability of the cell layers to respond in electrically semi-independent ways, which also speaks against a strong cell-cell coupling via MEGJs in the vascular wall.

The local action of an agonist-induced CVR may involve several factors. ACh, for instance, produces different endothelium-derived hyperpolarizing factors at the local site, and it appears likely that the cell-cell communication may involve both MEGJs and secreted factors. In the conducted region, however, it appears most likely that MEGJ plays a dominant role in the communication between endothelial and smooth muscle cells. The rapid spread of the CVR up and downstream from the stimulation site strongly indicates a direct electrical coupling via MEGJs between the cell layers. Secretion of diffusible factors from the endothelium would be expected to produce a much slower vascular response compared to what have been observed experimentally. Such a pharmacomechanical dilation has only been reported following a slow, short-range $\mathrm{Ca}^{2+}$-wave in the EC layer $[12,35]$. That CVR-inducing agonists may produce a range of vasoactive substances locally, whereas the conducted region depends on functional MEGJs for radial signalling not only agrees with most experimental evidence, e.g., $[15,16,24,37,39]$ but also provides an explanation of the strong conduction observed by stimulation with agonists like ACh or bradykinin $[9,14]$ as seen in Fig. 5.

Model limitations Limitations related to this study include (general limitations are described elsewhere [19, 25, 34]): (1) Some ion transporters are modeled as ohmic resistors that show no current saturation, i.e., such ion transporter models are increasingly active outside the physiological relevant regions. As this may compromise model behavior in extreme cases, care was taken to avoid extreme potentials. In other words, outside the physiological $\mathrm{V}_{\mathrm{m}}$-range of rat mesenteric arterioles, the model is questionable as it is only optimized to data within this $\mathrm{V}_{\mathrm{m}}$-range. (2) The steady state criterion applied here (see SI) does not ensure a mathematical steady state but terminates at a sufficiently slow moving pseudo-steady state. However, this is probably also the case for "real" systems which are never allowed to relax to steady state. (3) Finally, it should be noted that no variation in MEGJ distribution was included in these simulations. MEGJs may significantly influence the $\mathrm{V}_{\mathrm{m}}$-profile in the (poorly conducting) SMC layer [20] as a full-fledged vasomotor response depends on sufficient charge reaching (or being generated in) this layer.

\section{Conclusions}

Circumstances leading to heterogeneity in electrical spread along the arteriolar wall were studied using a computational approach. Within a single type of vessel, the stimulated cell type(s) and current generation ability produce variation. In particular, depolarization activates highly dissipating repolarizing currents. Simultaneous stimulation of both cell layers augments electrical spread. Between vascular beds, conduction efficiency additionally depends on variations in electrophysiology and morphology and can be altered by global modulations, e.g., changes in either flow, pressure 
or globally applied agonists. Finally, because electrical signals spread through the well-coupled endothelial cell layer electrical cell-cell variation is largely homogenized.

The preceding discussion leads to the following "principles of conduction" for achieving a strong electrically induced vasomotor response in a vessel (provided the EC layer is the primary electrical pathway):

1. The electrical spread induced by an agonist depends on both activation of particular cell type(s) and on the amount of current induced locally.

2. Conservation of charge: Overall, an efficient CVR depends on charge "staying" in the EC layer, i.e., a limited dissipation of charge to the extracellular medium or to the SMC layer.

3. The vasomotor response depends on (1) charge spread to the SMC layer and (2) how efficiently this charge translates into force generation.

For example, SMC-SMC coupling needs be low to promote a strong $\mathrm{V}_{\mathrm{m}}$-response as well as a localized vasomotor response. Yet, coupling need be high enough to smoothen the $\mathrm{V}_{\mathrm{m}}$-response in the SMC layer, e.g., charge SMCs without MEGJs.

In conclusion, numerous factors determine the conduction efficacy of a given stimulus. This explains the observed heterogeneity in conduction among independent studies. However, the basal biophysical considerations above provide a unifying mechanistic understanding of the electrical process.

Acknowledgments The work is part of the Dynamical Systems Interdisciplinary Network, University of Copenhagen. BOH is supported by Arvid Nilssons Fond and the Danish Council for Independent Research (DFF - 1333-00172). DGW is supported by an operating grant from the Canadian Institute of Health Research. The authors would like to thank Preben Graae Sørensen for the use of his computing cluster.

\section{Conflict of interests None}

\section{References}

1. Bagher P, Segal SS (2011) Regulation of blood flow in the microcirculation: Role of conducted vasodilation. Acta Physiol (Oxf) 202(3):271-284

2. Behringer EJ, Segal SS (2012) Tuning electrical conduction along endothelial tubes of resistance arteries through ca2+-activated $\mathrm{k}+$ channels. Circ Res 110(10):1311-1321

3. Boettcher M, de Wit C (2011) Distinct endothelium-derived hyperpolarizing factors emerge in vitro and in vivo and are mediated in part via connexin 40-dependent myoendothelial coupling. Hypertension 57(4):802-808

4. Brayden JE, Nelson MT (1992) Regulation of arterial tone by activation of calcium-dependent potassium channels. Science 256(5056):532-535
5. Carter TD, Ogden D (1994) Acetylcholine-stimulated changes of membrane potential and intracellular ca2+ concentration recorded in endothelial cells in situ in the isolated rat aorta. Pflugers Arch 428(5-6):476-484

6. Cole WC, Welsh DG (2011) Role of myosin light chain kinase and myosin light chain phosphatase in the resistance arterial myogenic response to intravascular pressure. Arch Biochem Biophys 510(2):160-173

7. Coleman HA, Tare M, Parkington HC (2001) Edhf is not k+ but may be due to spread of current from the endothelium in guinea pig arterioles. Am J Physiol Heart Circ Physiol 280(6):H2478H2483

8. Delashaw JB, Duling BR (1991) Heterogeneity in conducted arteriolar vasomotor response is agonist dependent. Am J Physiol 260(4 Pt 2):H1276-H1282

9. de Wit C (2010) Different pathways with distinct properties conduct dilations in the microcirculation in vivo. Cardiovasc Res 85(3):604-613

10. de Wit C, Boettcher M, Schmidt VJ (2008) Signaling across myoendothelial gap junctions-Fact or fiction? Cell Commun Adhes 15(3):231-245

11. Diep HK, Vigmond EJ, Segal SS, Welsh DG (2005) Defining electrical communication in skeletal muscle resistance arteries: a computational approach. J Physiol 568(Pt 1):267-281

12. Domeier TL, Segal SS (2007) Electromechanical and pharmacomechanical signalling pathways for conducted vasodilatation along endothelium of hamster feed arteries. J Physiol 579(Pt 1):175-186

13. Dora KA, Gallagher NT, McNeish A, Garland CJ (2008) Modulation of endothelial cell kca3.1 channels during endotheliumderived hyperpolarizing factor signaling in mesenteric resistance arteries. Circ Res 102(10):1247-1255

14. Emerson GG, Neild TO, Segal SS (2002) Conduction of hyperpolarization along hamster feed arteries: Augmentation by acetylcholine. Am J Physiol Heart Circ Physiol 283(1): H102-H109

15. Emerson GG, Segal SS (2000) Electrical coupling between endothelial cells and smooth muscle cells in hamster feed arteries: Role in vasomotor control. Circ Res 87(6):474-479

16. Emerson GG, Segal SS (2000) Endothelial cell pathway for conduction of hyperpolarization and vasodilation along hamster feed artery. Circ Res 86(1):94-100

17. Haas TL, Duling BR (1997) Morphology favors an endothelial cell pathway for longitudinal conduction within arterioles. Microvasc Res 53(2):113-120

18. Hald BO, Hendriksen MG, Sørensen PG (2013) Programming strategy for efficient modeling of dynamics in a population of heterogeneous cells. Bioinformatics 29(10):1292-1298

19. Hald BO, Jacobsen JCB, Braunstein TH, Inoue R, Ito Y., Sørensen PG, Holstein-Rathlou NH, Jensen LJ (2012) Bkca and kv channels limit conducted vasomotor responses in rat mesenteric terminal arterioles. Pflugers Arch 463(2):279-295

20. Hald BO, Jacobsen JCB, Sandow SL, Holstein-Rathlou NH, Welsh DG (2014) Less is more: minimal expression of myoendothelial gap junctions optimizes cell-cell communication in virtual arterioles. J Physiol 592(Pt 15):3243-3255

21. Hald BO, Jensen LJ, Sørensen PG, Holstein-Rathlou NH, Jacobsen JCB (2012) Applicability of cable theory to vascular conducted responses. Biophys J 102(6):1352-1362

22. Hanani M (1997) Microscopic analysis of pressure ejection of drugs from micropipettes. J Basic Clin Physiol Pharmacol 8(12):57-71

23. Hill CE, Phillips JK, Sandow SL (2001) Heterogeneous control of blood flow amongst different vascular beds. Med Res Rev 21(1): $1-60$ 
24. Hungerford JE, Sessa WC, Segal SS (2000) Vasomotor control in arterioles of the mouse cremaster muscle. FASEB J 14(1):197-207

25. Kapela A, Bezerianos A, Tsoukias NM (2009) A mathematical model of vasoreactivity in rat mesenteric arterioles: I. myoendothelial communication. Microcirculation 16(8):694713

26. Kapela A, Nagaraja S, Tsoukias NM (2010) A mathematical model of vasoreactivity in rat mesenteric arterioles. ii. conducted vasoreactivity. Am J Physiol Heart Circ Physiol 298(1): $\mathrm{H} 52-\mathrm{H} 65$

27. Kurjiaka DT, Segal SS (1995) Conducted vasodilation elevates flow in arteriole networks of hamster striated muscle. Am J Physiol 269(5 Pt 2):H1723-H1728

28. Lidington D, Ouellette Y, Tyml K. (2000) Endotoxin increases intercellular resistance in microvascular endothelial cells by a tyrosine kinase pathway. J Cell Physiol 185(1):117125

29. Loewer A, Lahav G (2011) We are all individuals: Causes and consequences of non-genetic heterogeneity in mammalian cells. Curr Opin Genet Dev 21(6):753-758

30. McCloskey KD, Toland HM, Hollywood MA, Thornbury KD, McHale NG (1999) Hyperpolarisation-activated inward current in isolated sheep mesenteric lymphatic smooth muscle. J Physiol 521 Pt 1:201-211

31. Nilius B, Viana F, Droogmans G (1997) Ion channels in vascular endothelium. Annu Rev Physiol 59:145-170

32. Sandow SL, Haddock RE, Hill CE, Chadha PS, Kerr PM, Welsh DG, Plane F. (2009) What's where and why at a vascular myoendothelial microdomain signalling complex. Clin Exp Pharmacol Physiol 36(1):67-76

33. Siegl D, Koeppen M, Wölfle SE, Pohl U, de Wit C (2005) Myoendothelial coupling is not prominent in arterioles within the mouse cremaster microcirculation in vivo. Circ Res 97 (8):781-788
34. Silva HS, Kapela A, Tsoukias NM (2007) A mathematical model of plasma membrane electrophysiology and calcium dynamics in vascular endothelial cells. Am J Physiol Cell Physiol 293(1):C277-C293

35. Tallini YN, Brekke JF, Shui B, Doran R, Hwang SM, Nakai J, Salama G, Segal SS, Kotlikoff MI (2007) Propagated endothelial ca2+ waves and arteriolar dilation in vivo: Measurements in cx40bac gcamp2 transgenic mice. Circ Res 101(12):1300-1309

36. Thakali KM, Kharade SV, Sonkusare SK, Rhee SW, Stimers JR, Rusch NJ (2010) Intracellular ca2+ silences 1-type ca2+ channels in mesenteric veins: Mechanism of venous smooth muscle resistance to calcium channel blockers. Circ Res 106(4):739-747

37. Tran CHT, Taylor MS, Plane F, Nagaraja S, Tsoukias NM, Solodushko V, Vigmond EJ, Furstenhaupt T, Brigdan M, Welsh DG (2012) Endothelial ca2+ wavelets and the induction of myoendothelial feedback. Am J Physiol Cell Physiol 302(8):C1226$\mathrm{C} 1242$

38. Tran CHT, Vigmond EJ, Goldman D, Plane F, Welsh DG (2012) Electrical communication in branching arterial networks. Am J Physiol Heart Circ Physiol 303(6):H680-H692

39. Tran CHT, Vigmond EJ, Plane F, Welsh DG (2009) Mechanistic basis of differential conduction in skeletal muscle arteries. J Physiol 587(Pt 6):1301-1318

40. Welsh DG, Segal SS (2000) Role of edhf in conduction of vasodilation along hamster cheek pouch arterioles in vivo. Am J Physiol Heart Circ Physiol 278(6):H1832-H1839

41. Wölfle SE, Chaston DJ, Goto K, Sandow SL, Edwards FR, Hill CE (2011) Non-linear relationship between hyperpolarisation and relaxation enables long distance propagation of vasodilatation. J Physiol 589(Pt 10):2607-2623

42. Yamamoto Y, Klemm MF, Edwards FR, Suzuki H (2001) Intercellular electrical communication among smooth muscle and endothelial cells in guinea-pig mesenteric arterioles. J Physiol 535(Pt 1):181-195 